\title{
OS PRECEDENTES JUDICIAIS E A RATIO DECIDENDI: O EXEMPLO DA ADPF 130/DF
}

\author{
JUDICIAL PRECEDENTS AND RATIO DECIDENDI: \\ THE ADPF 130/DF CASE
}

\section{LOS PRECEDENTES JUDICIALES Y LA RATIO DECIDENDI: EL EJEMPLO DE ADPF 130/DF}

\author{
GUSTAVO OSNA \\ https://orcid.org/0000-0001-5723-1166 / http://lattes.cnpq.br/6404084238253036 / gustavo_osna@hotmail.com \\ Pontifícia Universidade Católica do Rio Grande do Sul - PUC/RS \\ Porto Alegre, RS, Brasil.
}

\begin{abstract}
RESUMO
O processo civil brasileiro contemporâneo vem, constantemente, colocando a matéria dos precedentes vinculantes como um dos seus importantes pontos de análise. 0 presente artigo se insere nessa quadra, avaliando o que motiva esse discurso e indicando a necessidade de que se compreenda a dimensão objetiva de um precedente vinculante, identificando, em um contexto decisório, o que deve ou não vincular. Ganham força, então, conceitos como ratio decidendi e holding. Na sequência, apresenta-se a ADPF 130/DF como um exemplo concreto em que a mácompreensão desse pilar vem gerando uma leitura distorcida do posicionamento atingido pelo Supremo Tribunal Federal.
\end{abstract}

Palavras-chave: Precedentes vinculantes; ratio decidenci; cultura processual; liberdade de imprensa.

\begin{abstract}
Nowadays, Brazilian civil litigation is constantly recognizing the binding power of judicial precedents as a relevant issue of investigation. This article is framed on this background, observing what raises such argument and pointing the essentiality of understanding the objective dimension of a precedent - identifying which elements of a decision must bind. Therefore, concepts as ratio decidendi or holding become pertinent. After that, I present the ADPF 130/DF as a concrete case where the wrong identification of the ratio decidendi is causing wrong analysis of the Supremo Tribunal Federal's opinion.
\end{abstract}

Keywords: Binding precedents; ratio decidendi; civil litigation and culture; freedom of press.

\section{RESUMEN}

El proceso civil brasileño contemporáneo está constantemente colocando el asunto de los precedentes vinculantes como uno de sus puntos de análisis importantes. Este artículo se inserta en esta sección, evaluando qué motiva este discurso e indicando la necesidad de comprender la dimensión objetiva de un precedente vinculante: identificar, en un contexto de toma de decisiones, lo que debe o no vincular. Adquieren fuerza, entonces, conceptos como la ratio decidendi y lo holding. En la secuencia, el ADPF 130 / DF se presenta como un ejemplo concreto en el que la falta de comprensión de este pilar ha generado una lectura distorsionada de la posición alcanzada por el Supremo Tribunal Federal.

Palabras clave: precedentes vinculantes; ratio decidenci; cultura procesal; Libertad de prensa 


\section{SUMÁRIO}

INTRODUÇAO; 1 OS PRECEDENTES E A SUA EXTENSÃO: DUAS BREVES NOTAS; 1.10 que os "Precedentes Judiciais" são?; 1.2 A Extensão da Vinculação: o Problema da Ratio Decidendi; 20 EXEMPLO DA ADPF 130/DF: A OBSCURIDADE DA RATIO E O "PRECEDENTE TRAIÇOEIRO"; 2.1 A Lei de Imprensa e a ADPF 130/DF; 2.20 Julgamento da ADPF 130/DF e o Posicionamento do Supremo Tribunal Federal; 2.3 A ADPF 130/DF e sua Ratio em Perspectiva; CONCLUSÃO; REFERÊNCIAS.

\section{INTRODUÇÃO}

Ao mesmo tempo em que o processo civil vem se deparando recentemente com novos dilemas e desafios, tem incumbido ao operador da matéria desenvolver e efetivar as estruturas necessárias para o desempenho dessas atribuições. Pensar em alternativas e em percursos capazes de dar conta da realidade da disciplina. É nesse percurso que ingressa o discurso dos precedentes vinculantes, cujo avanço em nosso ambiente jurídico, ao longo dos últimos anos, é flagrante.

O presente estudo pretende se inserir nessa quadra, analisando um elemento específico relacionado à temática em questão: a fixação da sua dimensão objetiva, permitindo o devido exame daquilo que, em um contexto decisório, pode ou não se tornar vinculante. Trata-se, enfim, de partir da compreensão daquilo que um precedente é para verificar em que extensão ele deve atuar. Entra em cena a noção de ratio decidendi, revelando sua pertinência para o tópico em questão. É que somente diante da devida percepção desse elemento é possível extrair de uma decisão, verdadeiramente, seu potencial para enriquecimento do ordenamento jurídico.

Para alcançar esse objetivo, o presente ensaio apresenta, primeiramente, uma breve noção conceitual ligada às ideias de precedentes e de ratio decidendi. Com isso, procura-se demonstrar tanto o papel ocupado por esse argumento teórico quanto, e especialmente, a proeminência assumida pela segunda noção em sua efetivação. Afinal, somente sabendo o que deve se tornar vinculante é viável aplicar coerentemente essa vinculação.

$\mathrm{Na}$ sequência, o artigo demonstra um exemplo concreto de nosso cenário forense, a ADPF 130/DF, em que a ausência desse crivo inicial parece ter se verificado, permitindo a eternização de uma má-interpretação de julgamento proferido em sede de Corte Suprema. Nessa ocasião, colocou-se em debate a recepção constitucional de nossa antiga Lei de Imprensa. 
Contudo, após o julgado, não foi incomum se tentar extrair dele algo que não parece, verdadeiramente, ter composto suas razões de decidir.

Para cumprir esse percurso, o artigo se vale de um método dedutivo tradicional, adotando como ponto de partida a bibliografia ligada à temática e lançando mão dos conceitos e das ideias nela construídos para compreender o estado de arte de cada um dos elementos nucleares à análise. Do mesmo modo, o julgamento proferido pelo Supremo Tribunal Federal por ocasião da Arguição de Descumprimento de Preceito Fundamental acima indicada é colocado em perspectiva, procurando-se oferecer uma abordagem cética à sua análise ${ }^{1}$. Com isso, viabiliza-se que o julgamento seja compreendido com "olhares de madeira", deixando-se de lado as primeiras impressões a ele relacionadas e procurando-se investigar com maior verticalidade seus principais pilares ${ }^{2}$.

\section{OS PRECEDENTES E A SUA EXTENSÃO: DUAS BREVES NOTAS}

\subsection{0 que os "Precedentes Judiciais" são?}

O primeiro ponto a ser elucidado, então, possui natureza predominantemente conceitual. Em poucas palavras, trata-se de esclarecer o que se entende aqui por precedente judicial. A tarefa poderia parecer simplória, mas se torna imprescindível em nosso contexto. Isso, seja pela popularização contemporânea da expressão, seja pela sua questionável utilização no contexto do Código de Processo Civil de 2015.

Realmente, conforme já identificado por autores como Luiz Guilherme Marinoni, o avanço do discurso dos precedentes na realidade brasileira é responsável por fazer com que, não raramente, lance-se mão desse vocábulo para fazer menção a aspectos que com ele possivelmente não se confundem ${ }^{3}$. Sob esse viés, torna-se comum a subsunção dos precedentes

\footnotetext{
${ }_{1}^{1}$ Propondo essa espécie de análise, de modo geral para o processo civil, ver, OSNA, Gustavo. Processo civil, cultura e proporcionalidade: análise crítica da teoria processual. São Paulo: Ed. RT, 2017.

${ }^{2} \mathrm{O}$ termo é trazido por Carlo Ginzburg para ressaltar uma postura de estranhamento, rompendo a apatia ínsita ao cotidiano. Na obra do autor, sua utilização possui ênfase especialmente transcultural, ressaltando a importância de que ao apreciarmos aspectos que nos são diversos - e, por isso, poderiam ser prontamente criticados - tenhamos um olhar de reflexão. Veja-se, GINZBURG, Carlo. Olhos de madeira novas reflexões sobre a distância. Trad. Eduardo Brandão. São Paulo: Companhia das Letras, 2001.

3 Ver, por todos, MARINONI, Luiz Guilherme. Precedentes obrigatórios. 3 ed. São Paulo: Ed. RT, 2013. Também, MARINONI, Luiz Guilherme. O STJ enquanto corte de precedentes: recompreensão do sistema processual da Corte Suprema. 3 ed. São Paulo: Ed. RT, 2017.
} 
a ideias como as de súmula ou de jurisprudência, algo que Daniel Mitidiero argumenta não possuir maior sustentação sob um ponto de vista técnico ${ }^{4}$.

Do mesmo modo, esse tipo de raciocínio é estimulado pelo texto do atual diploma processual civil. $\mathrm{E}$ isso porque, por mais que o exame minucioso do texto legislativo e das suas opções seja estranho ao objeto do presente trabalho, pode-se salientar brevemente que parece haver ali uma aproximação entre a ideia de precedentes e algumas técnicas processuais específicas, como os incidentes de coletivização de interesses ou a edição de enunciados sumulares ${ }^{5}$. Além disso, também é cabível destacar que a codificação apresenta natureza opaca no que toca à determinação da instância capaz de editar um precedente com vinculação vertical. Em qualquer dos casos, consolida-se raciocínio que não escapa de críticas doutrinárias ${ }^{6}$.

\footnotetext{
${ }^{4}$ Ao esmiuçar a questão, o autor salientou que "jurisprudência, precedentes e súmulas são conceitos que não podem ser confundidos (...) tradicionalmente, a jurisprudência consubstancia-se na atividade de interpretação da lei desempenhada pelas cortes para solução de casos, cuja múltipla reiteração gera a uniformidade (...) o novo Código claramente outorga outro sentido ao termo jurisprudência - ao menos para determinados casos.Para essas situações, o novo Código exige a sua ressignificação: isso porque, ao emprestar força vinculante aos julgamentos de casos repetitivos e àqueles tomado em incidente de assunção de competência (art. 927, III) no âmbito das Cortes de Justiça e dispensar a múltipla reiteração (...) o direito brasileiro rompe em grande parte com a caracterização tradicional da jurisprudência 0 mesmo ocorre com as súmulas. Quando as súmulas eram vistas apenas como um método de trabalho capaz de ordenar e facilitar a tarefa dos juízes - note-se que aí os destinatários das súmulas eram apenas e tão somente os próprios órgãos judiciais que compunham os tribunais que as emanavam - bastava redigi-las de forma abstrata, sem qualquer alusão aos casos concretos aos quais ligadas. Ao reconhecer as súmulas como guias para a interpretação do direito (...) previu-se o dever de identificação e de congruência (...) Além de ressignificar a jurisprudência e as súmulas, o novo Código introduz o conceito de precedentes. Os precedentes não são equivalentes às decisões judiciais. Eles são razões generalizáveis que podem ser identificadas a partir das decisões judiciais". MITIDIERO, Daniel. Precedentes, Jurisprudência e Súmulas no Novo Código de Processo Civil Brasileiro. In. Revista de Processo. v.245. São Paulo: Ed. RT, 2015.

${ }^{5} \mathrm{~A}$ crítica relacionada à opção legislativa, assim como sua pouca afinidade funcional com os objetivos que deveriam nortear uma estrutura de precedentes, é realizada por Streck e Abboud ao comentar o art. 927 do Código de Processo Civil. Em suas palavras, "o fato de o art. 927 do CPC elencar diversos provimentos que passarão a ser vinculantes, não pode nos induzir a leitura equivocada de imaginar que a súmula, 0 acórdão que julga o IRDR ou oriundo de recurso (especial ou extraordinário repetitivo) são equiparáveis à categoria do genuíno precedente do common law (...) o sistema genuíno de precedentes ingles é criador de complexidade. 0 que o CPC/2015 faz é criar provimentos judiciais vinculantes cuja função é reduzir a complexidade judicial para enfrentar o fenômeno brasileiro da litigiosidade repetitiva". Assim, STRECK, Lenio Luiz. NUNES, Dierle. CUNHA, Leonardo Carneiro da. (Orgs.). FREIRE, Alexandre (Coord.). Comentários ao Código de Processo Civil. 2 ed. São Paulo: Saraiva, 2017. Ainda analisando o sistema estabelecido pelo legislador de 2015, a partir de um conceito amplo de "padrões decisórios", ver CÂMARA, Alexandre Freitas. Levando os padrões decisórios a sério: formação e aplicação de precedentes e enunciados de súmula. São Paulo: Atlas, 2018. Por fim, no que toca às técnicas de julgamento de casos repetitivos e seu enquadramento no processo coletivo, ver ARENHART, Sérgio Cruz. OSNA, Gustavo. Curso de Processo Civil Coletivo. 2. ed. rev. atual e ampl. São Paulo: Ed. RT, 2020.

${ }^{6}$ Analisando especificamente o art. 926 do diploma processual civil, visto por alguns como um importante passo para a valorização dos precedentes em nosso sistema jurídico, Daniel Mitidiero pontua que, "embora inequivocamente bem intencionado, o dispositivo padece de cinco problemas teóricos. A uma, fala em tribunais indistintamente, sem atentar que existe uma divisão de trabalho bastante clara entre as Cortes de Justiça e as Cortes Supremas no ordenamento jurídico brasileiro. A duas, institui um dever de
} 
Em que, porém, consistiria um precedente? Como atribuir o devido enquadramento a esse conceito, compreendendo-o em sua totalidade?

Esmiuçando as questões, é importante destacar, primeiramente, que a análise dos precedentes judiciais pela doutrina brasileira não constitui questão inaugurada pelo Código de Processo Civil de 2015. Pelo contrário, ainda que a positivação do diploma e os debates a ele relacionados tenham estimulado a análise da matéria ${ }^{7}$, há estudos pretéritos que já identificavam enfaticamente a sua relevância ${ }^{8}$. Isso, especialmente, devido ao seu inequívoco traço teleológico - algo cuja verificação em sede comparada é tradicional.

É exatamente partindo desse ângulo que a compreensão do que os precedentes são nos parece diretamente relacionada ao próprio entendimento do propósito a que se prestam. Como consequência, a análise passa a apresentar um pano de fundo eminentemente funcional. Entender o que os precedentes são passado, antes de tudo, por assimilar os motivos que levaram ao seu desenvolvimento.

Para enfrentar esse dilema, a chave central reside na assunção de importância assumida no Direito, ao longo do último século, pela ideia de interpretação. Pelo reconhecimento de que de um mesmo texto podem ser razoavelmente extraídas diferentes normas, gerando um constante risco de inconsistências ${ }^{9}$. Afinal, diante dessa percepção, o mito da completude do ordenamento normativo é colocado na linha de tiro: a lei não oferece resposta para tudo, e,

uniformização, nada obstante seja conhecida a ligação do termo a uma função de simples controle que era exercida pelas cortes de vértice em um determinado momento da história. A três, alude genericamente à jurisprudência, sem se preocupar com eventuais distinções que podem existir entre os termos jurisprudência, súmula e precedentes, empregados igualmente em seus parágrafos. A quatro, refere que os tribunais têm o dever de manter a jurisprudência estável, quando na verdade esse é apenas um dos seus deveres no que tange à necessidade de prover segurança jurídica. A cinco, endossa uma proposta teórica bastante específica a respeito do conceito de direito ao determinar que a jurisprudência deva ser íntegra". Idem. p.334.

${ }^{7}$ Ver na doutrina nacional dos precedentes, de maneira exemplificativa e em acréscimo às demais obras já referidas no presente ensaio, ZANETI JR., Hermes. 0 valor vinculante dos precedentes. Salvador: JusPodim, 2015. PUGLIESI, William. Precedentes e a civil law brasileira. São Paulo: Ed. RT, 2016. PEREIRA, Paula Pessoa. Legitimidade dos precedentes. São Paulo: Ed. RT, 2014.

${ }^{8}$ Nesse sentido, veja-se, de modo emblemático, que a primeira edição da obra "Precedentes Obrigatórios, de autoria de Luiz Guilherme Marinoni (vide nota 3) possuiu publicação em 2009. E nessa ocasião o teórico já expunha os propósitos inerentes ao mecanismo - explorando suas potencialidades e demonstrando aspectos relacionados à sua dinâmica.

9 Nas palavras de Frank, que "the problem is, in part, one of what today we call "semantics". Words serve as symbols. As such, necessarily they are somewhat compressed, condensed. Does the legislature's compression which omits some particulars, indicate an intention to omit them? The judges must determine the proper limits of expansion of the condensed symbols. Judges often differ among themselves as to the appropriate amount of such expansion. The varieties of human experiences are legion. They cannot be dealt with in mathematically. What, for instance, does the word "value" or the word "employees" mean when found in a statute? Were a legislature to try to tie down the courts by over-precise words, it would often defeat itself". FRANK, Jerome. Courts on Trial. New York: Princeton University Press, 1949. p.294. 
mais que isso, a partir dela sequer é possível se afirmar categoricamente que somente uma resposta poderia ser casuisticamente alcançada ${ }^{10}$.

Colocando essa constatação em outros termos, assim, o que se vê é que um mesmo enunciado normativo, ao ser aplicado por juízes diversos, pode sê-lo também de maneira diversa. Avaliando o preenchimento ou não da função social do contrato diante de determinada operação comercial, é viável que magistrados cheguem a conclusões diferentes, por mais que exista similitude entre as circunstâncias materiais. Observando o cabimento ou não de repetição em dobro por valores indevidamente pagos, é factível que situações idênticas, vivenciadas por uma pluralidade de consumidores, recebam respostas substancialmente diversas. Cada um desses aspectos demonstra que a pluralidade interpretativa deve ser vista como algo inevitável. Não obstante, a aceitação rigorosa de seus efeitos, sem que sejam adotadas medidas voltadas a mitigá-los, pode se mostrar patológica.

De fato, pelos exemplos acima já se pode perceber que a cisão entre texto e norma, ao superar a ideia de que o ordenamento normativo é capaz de regrar satisfatoriamente todas circunstâncias do mundo fático, também traz consigo uma consequência imediata: a possibilidade de que diferentes sujeitos, por mais que providos de situações similares, recebam respostas incompatíveis do órgão jurisdicional. Nesse cenário, nada assegura que o valor mínimo da igualdade possa ser preservado. Por decorrência, em um modelo preocupado com a tutela

\footnotetext{
10 Observando esse elemento, Schauer nota que o reconhecimento da abertura interpretativa faz com que um mesmo suporte possa ser compreendido de modo substancialmente diverso por diferentes atores. Problematizando a questão, o autor assim pontua: "under what circumstances will which officials be given the freedom to exercise their own judgment and make their own choices, and under what circumstances will that freedom be constrained or even mostly eliminated? When a judge is determining which custody decision is in the best interests of the child, for example, she might be faced with a choice between a wealthy mother who can provide the child with high-quality education, housing, recreation, and culture and a less wealthy father who appears to understand the child better than the mother. Under these circumstances, some judges would prefer the mother and others the father, but the basic idea of discretion is that neither of these decisions, given the "best interests of the child" standard, would be legally incorrect. People might criticize one or the other decision for being morally wrong, psychologically ignorant, or based on erroneous factual premises, and so it would not be correct to say that the two decisions are equally right. But it would be correct to say that the two decisions are equally legally right, and thus that either decision would, in the ordinary course of things, be upheld on appeal". Corroborando a questão, e valendo-se do próprio pensamento de Schauer, também Bruno Torrano percebe que a abertura de caminhos é consequência lógica da porosidade, afirmando que "é tarefa fácil imaginar situações em que, a despeito de a discussão envolver uma situação juridicamente regulada, há, de um lado, cuidado excessivo na argumentação, mas, de outro, continuam existindo possibilidades decisórias igualmente bem fundamentadas, que apontam para lado diverso. Eis, aí, outra ideia central da discricionariedade, que recomenda que esse termo seja utilizado em sentido amplo: a completa e fatal inexistência de critérios seguros para dizer que uma das decisões possíveis em um caso regulado é legalmente incorreta". SCHAUER, Fredericks. Thinking like a Lawyer - A new introduction to legal reasoning. Cambridge: Harvard University Press, 2009. p.190. TORRANO, Bruno. Do fato à legalidade: introdução à teoria analítica do direito. Rio de Janeiro: Lumen Juris, 2014. p.167
} 
desse valor, como ao menos declaradamente é o nosso ${ }^{11}$, cria-se uma lacuna a ser suprida pelo operador do Direito.

É precisamente nesse ponto, procurando de algum modo mitigar a insegurança, a ausência de previsibilidade e a quebra de isonomia que andam lado a lado com a insuficiência do texto legislativo, que o discurso dos precedentes judiciais passa a se inserir. Por meio deles, pretende-se trazer uma salvaguarda para as externalidades negativas da pluralidade interpretativa: se a existência de diferentes leituras a partir de um mesmo texto é inevitável, a única saída possível é procurar reconhecer uma das possíveis normas como aquela a ser uniformemente aplicável. É perceber que, por mais que outras análises fossem viáveis, é sistemicamente benéfico tomar somente uma delas como efetiva ${ }^{12}$.

A quem, porém, competiria a fixação de qual das diferentes interpretações cabíveis deveria ser aquela adotada pelo Judiciário? Qual seria a instância adequada para estabelecer esse elemento, conferindo maior segurança e equanimidade à atividade jurisdicional?

Em termos breves, consideramos que a resposta a esses questionamentos passa pela percepção de que um sistema efetivo de precedentes costuma exigir que um tribunal faça as vezes de Corte Suprema. Nesse caso, seu papel deixa de ser a resolução de casos ou a revisão de decisões, e passa a ser depositado, exatamente, na fixação de precedentes. 0 tema é exposto com vagar em nossa doutrina por Daniel Mitidiero, demonstrando como esse modelo de órgão jurisdicional difere daquele de Cortes Superiores, mais comum em nossa tradição ${ }^{13}$.

Em síntese, o dilema posto por Mitidiero dialoga em ampla medida com o design que, dentro de um sistema de precedentes vinculantes, deve ser assumido pelo órgão de vértice responsável pela sua fixação ${ }^{14}$. É que, de um modo geral, a dinâmica própria da tutela da unidade do direito imporia novos modais e novos olhares ao próprio Judiciário.

\footnotetext{
11 Fala-se em "ao menos declaradamente" tendo em vista que, como demonstrado por Marinoni, a possibilidade de tratar sujeitos em cidadão igual de maneira desigual pode ter sido exatamente um dos motivos pelos quais, em nossa construção histórica, forjou-se uma estrutura desprovida de precedentes vinculantes. Com isso, seria possível, casuisticamente, favorecer os interesses de determinados grupos ou sujeitos. Assim, MARINONI, Luiz Guilherme. A Ética dos Precedentes. São Paulo: Ed. RT, 2014.

${ }_{12}$ Cabe destacar, contudo, que a previsibilidade sistêmica trazida pelos precedentes não é absoluta - seja pela sua própria mutabilidade, seja pelo fato de, casuisticamente, também a sua estrutura e o seu âmbito de aplicabilidade dever ser objeto de interpretação. 0 aspecto não esvazia a pertinência do recurso aos precedentes, mas deve trazer importantes temperos para a sua aplicação. Nesse sentido, ver, KOZEL, Randy J. Precedent and Reliance. In. Emory Law Journal. v.62. Atlanta: Emory University School of Law 2013. p.1459 e ss.

13 Ver, sobre o tema, MITIDIERO, Daniel. Cortes Superiores e Cortes Supremas: do Controle à Interpretação, da Jurisprudência ao Precedente. 2. ed. rev. atual e ampl. São Paulo: Ed. RT, 2014.

${ }_{14}$ Nas palavras do autor, "por debaixo da questão ligada ao precedente judicial pulsa o problema de radical importância atinente ao apropriado delineamento do papel das cortes judiciárias, isto é, ao dimensionamento das adequadas funções que devem ser por elas desempenhadas no Estado
} 
Aprofundando a questão, Mitidiero indica que, de maneira tradicional, diferentes tribunais de vértice acabaram estruturando sua atuação como instâncias de revisão de decisões judiciais. Sob esse viés, agiriam de maneira predominantemente responsiva e com um olhar coerentemente limitado ao próprio caso revisto. 0 ponto principal a ser enfrentado seria a decisão ali proferida, fazendo com que a Corte não mais fizesse do que oportunizar uma reanálise de seu conteúdo; do que agir nas palavras do autor, como uma Corte Superior ${ }^{15}$.

Não obstante, a efetivação dos precedentes exigiria uma alteração significativa nesse modal. $E$ isso porque, para permitir seu pleno funcionamento, seria preciso ter em mente que $o$ tribunal de vértice, ao apreciar determinada disputa, passaria a irradiar efeitos que a ela não se limitam. Sua atuação disporia de maior destaque e protagonismo, assumindo papel relevante na regulação da sociedade, ao enriquecer o ordenamento jurídico e possuindo impacto mais acentuado. Por força disso, deveria se valer de um olhar provido de natureza mais prospectiva, fazendo com que a singela revisão do caso, na melhor das hipóteses, fosse apenas um caminho para o exercício de outras funções pelo órgão. Somente assim seria possível agir como uma verdadeira Corte Suprema ${ }^{16}$, viabilizando os benefícios que um sistema de precedentes deseja alcançar.

\footnotetext{
Constitucional. E é exatamente por essa razão que não é possível teorizar frutiferamente o processo civil longe dos problemas atinentes à organização judiciária. Para que o processo civil tenha condições de ser um instrumento idôneo para a tutela dos direitos tanto em uma dimensão particular como geral, é imprescindível o exame do papel das cortes judiciárias no Estado Constitucional”. Idem. p.31.

15 "A Corte Superior - tomada como um modelo de corte de vértice da organização judiciária - caracterizase por pressupor, do ponto de vista da teoria do direito, a identificação entre texto, norma e regra jurídica (...) sendo competente para controlar a legalidade de todas as decisões a ela submetidas. A função que a Corte Superior desempenha é reativa, de modo que visa a controlar a aplicação da legislação caso a caso realizada pelos juízes ordinários, preocupando-se apenas com o passado (...) a jurisprudência uniforme serve como meio pelo qual a Corte pode desempenhar a função de controle de legalidade da decisão recorrida. A eficácia das decisões da Corte Superior é restrita às partes do caso concreto". Idem. p.35.

16 "A Corte Suprema - seja como corte de vértice da organização judiciária, seja como corte constitucional alocada pra fora da estrutura do Poder Judiciário - caracteriza-se por pressupor, do ponto de vista da teoria do direito, a dissociação entre texto e norma jurídica [...] é competente para orientar a aplicação do Direito mediante precedentes formados para a consecução da unidade do Direito. A função da Corte Suprema é proativa, de modo que via a orientar a interpretação e aplicação do Direito por parte da sociedade civil, por parte de seus próprios membros e por parte de todos os órgãos jurisdicionais, tendo a sua atuação direcionada para o futuro [...] a eficácia das decisões da Corte Suprema vincula toda a sociedade civil e todos os órgãos do Poder Judiciário, constituindo o precedente fonte primária do Direito". Idem. p.54.
} 


\subsection{A Extensão da Vinculação: o Problema da Ratio Decidendi}

Se no tópico anterior procurou-se conferir maior clareza à noção de precedentes, no presente momento considera-se igualmente necessário apresentar um ponto imprescindível para a devida atuação do instituto: a ideia de ratio decidendi. Em poucas palavras, se foi visto que o discurso dos precedentes possui como elemento central a tentativa de enriquecer o universo jurídico, fixando que manifestações advindas de Cortes Supremas devem possuir natureza vinculante, aqui se coloca na mesa outra indagação: a partir de determinada decisão proferida pelo tribunal de vértice, quais os aspectos que devem, ou não, vincular?

O problema posto, assim, possui relação com a dimensão objetiva de um precedente; com a delimitação de sua extensão; com a estipulação, enfim, do conteúdo a ser agregado à ordem jurídica, contribuindo com a tutela da unidade do ordenamento. É nessa seara que a noção de ratio decidendi é construída, mostrando-se essencial para que se possa falar seriamente na matéria sem incorrer em uma má-utilização do conceito e da teoria que lhe é basal.

De fato, a compreensão do tema passa pelo resgate de um aspecto sinalizado no tópico anterior: precedentes, ontologicamente, não se confundem com súmulas ou com dispositivos contidos em qualquer ato decisório oriundo do Judiciário. O seu propósito, ainda, não é simplificar o sistema normativo ou estabelecer ritos procedimentais específicos para o tratamento de casos análogos ${ }^{17}$. Pelo contrário, por meio de seu uso o que se almeja é enriquecer o ordenamento normativo; é estabelecer parâmetros capazes de conferir maior alcance e densidade ao sistema, em que pese a sua incompletude; é, enfim, reconhecer a pluralidade interpretativa inerente a cada texto legislativo, fixando uma das opções como aquela a ser amplamente adotada.

Isso demonstra o porquê de o precedente, verdadeiramente, não ser representado por uma decisão, mas sim por razões de decidir. O que importa, no arranjo decisório, são os elementos determinantes fixados pela Corte Suprema para viabilizar a aplicação de determinado enunciado. E é a esse arcabouço de razões, elementares à própria estruturação do posicionamento, que se atribuiu em sede comparada a denominação teórica de holding, ou de ratio decidendi ${ }^{18}$.

\footnotetext{
${ }^{17}$ Demonstrando o contraponto entre esse aspecto e as opções do Código de Processo Civil de 2015, ver notas 5 e 6, supra.

18 "The Supreme Court has described the holding of a case as including its "final disposition" in addition to "the preceding determinations 'necessary to that result.' Holdings must also be grounded
} 
Em um teste provido de importância didática, por mais que não raramente desafiado pela opacidade e pela penumbra presentes no contexto real, conforme notado por Kozel ${ }^{19}$, a fixação desse conjunto de elementos poderia ser extraída da seguinte indagação: ao observar-se determinado pronunciamento da Corte Suprema, quais os aspectos cuja remoção esvaziaria a própria conclusão alcançada? Seria essa a linha tênue que demarcaria a fronteira existente entre as razões de decidir (ratio decidenci) e os demais aspectos trazidos, de maneira colateral ou secundária, no contexto decisório (obter dictum). E, caso a situação tivesse aptidão para a formação de precedente, apenas os primeiros elementos deveriam se revestir de vinculação prospectiva geral ${ }^{20}$.

Considerando esse pano de fundo, reforça-se então a compreensão de que o precedente não se confunde com técnicas como a súmula. Isso, não apenas porque para a sua configuração essa técnica seria irrelevante, não compondo seu teste de pedigree, como ainda pelo fato o enunciado não necessariamente expressar as razões de decisão, atendo-se, muitas vezes, tão somente à externalização de determinado resultado. A confusão realizada pelo Código de Processo Civil de 2015 nesse ponto certamente gera embaraços à compreensão desse descompasso. Não obstante, a diferença deve ser lembrada, reforçando, ainda mais, a importância de que se compreenda o conteúdo objetivo a ser conferido a um precedente.

\section{EXEMPLO DA ADPF 130/DF: A OBSCURIDADE DA RATIO E 0 "PRECEDENTE TRAIÇOEIRO"}

\subsection{A Lei de Imprensa e a ADPF 130/DF}

Se no item anterior foi destacada a importância teórica da estipulação da ratio decidenci no âmbito de um precedente, compreendendo-se no que ele consiste e verificando-se em que extensão objetiva ele deve vincular, passa-se agora a demonstrar um exemplo concreto

in "the adjudicated facts"; hypothetical statements are the stuff of dicta. On this view, precedential effect attaches to the application of a targeted legal rule to a discrete set of facts that were actually presented in the underlying dispute". KOZEL. Randy J. The Scope of Precedent. In. Michigan Law Review. v.113. Ann Arbort: University of Michigan Law School, 2014. p.188.

19 Por esse motive, aliás, o autor problematiza a atual adoção desse critério como fator de segmentação para a vinculação dos precedentes - confrontando-o com a real utilização da técnica pela Suprema Corte dos Estados Unidos. Assim, passim, idem.

${ }^{20}$ Expondo a questão com minúcia sob a perspectiva do direito brasileiro, evidenciando sua polêmica também no âmbito do common law e demonstrando as dificuldades inerentes à própria fixação da ratio decidendi que marca determinada decisão, ver BUSTAMANTE, Thomas da Rosa. Teoria do precedente judicial: a justificação e a aplicação de regras jurisprudenciais. São Paulo: Noeses, 2012. 
em que a incerteza ligada a esse tópico marcou nossa atividade jurisdicional. Trata-se da possibilidade, ou da impossibilidade, de estipulação de parâmetros legislativos prévios que em alguma forma condicionem a liberdade de imprensa. 0 tema foi objeto de decisão pelo Supremo Tribunal Federal no âmbito da ADPF 130/DF, após exaustivo debate. Contudo, a incorreta compreensão das razões de decidir expostas pela Corte nessa oportunidade tem levado a leituras pouco precisas ao seu respeito.

Emoldurando o problema ${ }^{21}$, lembra-se brevemente que, por mais que o conceito de democracia possua fixação debatida em nossa realidade ${ }^{22}$, parece inequívoco que a sua concretização engloba alguma medida de participação. Que, sem que se oportunize ao sujeito tomar parte de certa maneira das decisões e dos debates pertinentes à esfera pública, não há como se forjar um ambiente democrático. É precisamente aqui, servindo como alicerce e pedrafundante para que esse agir disponha das informações e do senso crítico inerentes à sua efetivação, que a imprensa pode desempenhar papel fundamental, embasando a defesa da sua liberdade.

De fato, como Bollinger ${ }^{23}$ e Emerson ${ }^{24}$ destacaram décadas atrás ao comentar a Primeira Emenda à Constituição Estadunidense, as liberdades de expressão e de imprensa são peças-chave na formação de uma comunidade crítica, constatação já verificada na obra de Tocqueville ${ }^{25}$ e nas decisões de Oliver Wendell Holmes ${ }^{26}$. Ainda na doutrina, vemos o elemento alicerçado nos escritos de Rui Barbosa ${ }^{27} \mathrm{e}$, atualmente, exposto, ainda que com modulações e

210 presente capítulo sintetiza ideias expostas com maior vagar em OSNA, Gustavo. Entre a Teoria e a Concretização - Possibilidades, Limites e Funções para uma Nova Lei de Imprensa. In. Revista do Instituto dos Advogados do Paraná. v. 41. Curitiba: IAP, 2012. p.17-41.

${ }^{22}$ Sobre esse ponto, ver SARTORI, Giovanni. O que é democracia?. Curitiba: Instituto Atuação, 2017. Também, DIAMOND, Larry. O Espírito da Democracia. Curitiba: Instituto Atuação, 2015.

${ }^{23}$ Analisando a relevância da liberdade de imprensa, Bollinger salienta que, sem ela, "the public cannot receive all the information it needs - abour government actions or public issues - to exercise its sovereign powers", enfatizando a essencialidade de uma imprensa livre para a construção de um sistema democrático de governo. BOLLINGER, Lee C. Images of a Free Press. Chicago: The University of Chicago Press, 1991. p. 5.

${ }^{24}$ EMERSON, Thomas. The System of Freedom of Expression. New York: Random House, 1970.

${ }^{25}$ Neste sentido, TOCQUEVILLE, Alexis de. Democracy in America. Trad. Henry Reeve. V. 2. New York: Schocken Books, 1961.

${ }^{26}$ Naquela que se tornou a possivelmente mais famosa, proferida em 1919 em Abrams v. United States, Wendell Holmes enfatizou que a população "should be eternally vigilant against attempts to check the expression of opinions that we loathe and believe to be fraught with death, unless they so imminently threaten immediate interference with the lawful and pressing purposes of the law that an immediate check is required to save the country", delineando o caráter de excepcionalidade que uma eventual restrição à Primeira Emenda deveria apresentar.

27 Por todos, BARBOSA, Rui. A imprensa e o dever da verdade. São Paulo: Com-Arte - Editora da Universidade de São Paulo, 1990. 
fundamentos diversos, por autores da repercussão de Cass Sunstein ${ }^{28}$ e de Richard Posner ${ }^{29}$. Em suma, são inúmeras as obras que, mesmo dissonando em aspectos relacionados ao procedimento desta proteção, relacionam a defesa da liberdade de imprensa com o desenvolvimento de um arcabouço democrático.

Ocorre que, de maneira breve, pode-se dizer que a atuação da imprensa, por mais que imprescindível, convive em uma situação de conflito latente com a própria proteção de direitos fundamentais individuais. Essa situação é evidenciada ao notarmos que a propagação de uma notícia pode ensejar um abalo nítido ao noticiado e ferir a sua dignidade. Conforme percebido por Sunstein ao proferir palestra na Harvard Law School, por exemplo, a dispersão de rumores é ruinosa ao sujeito cuja identidade é veiculada, e a atuação da imprensa pode potencializar estes perigos ${ }^{30}$. Nestas hipóteses, coloca-se, de um lado, a proteção da liberdade de imprensa, mas, de outro, a defesa do indivíduo. Apresentada por Fábio Konder Comparato como finalidade central do Direito contemporâneo ${ }^{31}$ e eleita pela Constituição Federal de 1988 como fundamento de nossa República ${ }^{32}$. A situação, enfim, torna-se problemática, podendo impactar tanto a temática dos direitos de personalidade quanto elementos como a presunção de inocência na esfera penal ${ }^{33}$.

\footnotetext{
${ }^{28}$ Para apreensão do pensamento do autor e do papel que a liberdade de imprensa pode exercer em sua comunidade deliberativa, voltada ao constante debate dos "consensos incompletos" existentes no texto constitucional, veja-se SUNSTEIN, Cass R. Democracy and the problem of free speech. New York: Free Press, 1995.

${ }^{29}$ Construindo sua teoria da Análise Econômica do Direito, o autor - ao confrontar a questão da liberdade de imprensa - destaca que seu teor não se limita ao processo eleitoral e que se deve observar com ressalvas a possibilidade de limitação de seu conteúdo (considerando, inclusive, a existência fática de um "mercado de ideias" que poderia se autocontrolar). Cita-se, POSNER, Richard. Economic Analysis of Law. 2 ed. Boston: Little, Brown and Company, 1977. p.494; 541-542.

30 Para uma descrição dos diversos perigos indicados na exposição, ver LUX, Anthony. Spread of false information causes dangers, says Sunstein. Disponível em http://www.law.harvard.edu/news/spotlight/constitutional-law/sunstein-chair-lecture.html. Acesso em 13 de junho de 2019.

${ }^{31}$ Em suas palavras, "O primeiro postulado da ciência jurídica é o de que a finalidade-função ou razão de ser do Direito é a proteção da dignidade humana, ou seja, da nossa condição de único ser no mundo, capaz de amar, descobrir a verdade e criar a beleza". Ver, COMPARATO, Fábio Konder. O papel do juiz na efetivação dos direitos humanos. In. Direitos Humanos: Visões Contemporâneas. São Paulo: Associação Juízes para a Democracia, 2001. p.15-29.

32 "Art. $1^{\circ}$ A República Federativa do Brasil, formada pela união indissolúvel dos Estados e Municípios e do Distrito Federal, constitui-se em Estado Democrático de Direito e tem como fundamentos: (...) III - a dignidade da pessoa humana."

${ }^{33}$ A questão se revela na medida em que, como denota Antônio Magalhães Gomes Filho, essa "garantia constitucional não se revela somente no momento da decisão, como expressão da máxima in dubio pro reo, mas se impõe igualmente como regra de tratamento do suspeito, indiciado ou acusado, que antes da condenação não pode sofrer qualquer equiparação ao culpado; e, sobretudo, indica a necessidade de se assegurar, no âmbito da justiça criminal, a igualdade do cidadão no confronto com o poder punitivo, através de um processo "justo"”. E, visivelmente, a tutela desse valor pode colidir com o pleno exercício
} 
Enfim, diante dessa pluralidade de valores, o tratamento da situação pelo ordenamento jurídico pode representar um campo minado. E essa atividade foi desempenhada em nossa realidade, por décadas, pela Lei $n^{\circ}$ Lei $n^{\circ} 5.250$, publicada em 09 de fevereiro de 1967. Como é evidente, referido texto legislativo não foi imune ao contexto político então existente. Mais que isso, é notório que, posteriormente, o tratamento conferido pelo diploma foi ainda complementado pelo Decreto Lei $n^{\circ} 1077 / 70$, regulamentando a censura prévia.

Mesmo após o advento da Constituição Federal de 1988, porém, o texto legislativo manteve sua vigência. Isso, sem óbice da previsão constitucional expressa, então posta, de que “a manifestação do pensamento, a criação, a expressão e a informação, sob qualquer forma, processo ou veículo não sofrerão qualquer restrição, observado o disposto nesta Constituição", de que "nenhuma lei conterá dispositivo que possa constituir embaraço à plena liberdade de informação jornalística” e de que "é vedada toda e qualquer censura de natureza política, ideológica e artística". A redação é substancialmente mais ampla do que aquela vista na Constituição de 1967, conduzindo a uma coerente indagação: a Lei n 5.250/1967, teria, de fato, sido recepcionada pela Constituição Federal de 1988?

Foi precisamente esse o debate posto no âmbito da ADPF 130/DF, levando o Supremo Tribunal Federal a se debruçar detidamente sobre o tema, em uma de suas mais célebres mas, em nossa visão, também mais incompreendidas manifestações.

\subsection{Julgamento da ADPF 130/DF e o Posicionamento do Supremo Tribunal Federal}

Sintetizando de maneira breve a tramitação da medida, é possível destacar primeiramente que, ao proferir seu voto, o relator designado para o feito, Ministro Carlos Ayres Britto ${ }^{34}$, procurou conformar de início a própria ideia de imprensa, tratando-a como atividade e como entidade, para se aproximar de seu caráter informativo da opinião pública e enaltecer suas funções de revelação e de controle em uma civilidade avançada. Sua atuação livre seria complementar à cidadania e à democracia ${ }^{35}$, justificando o fato de a proteção desta liberdade

da liberdade de imprensa - dado o amplo potencial para que, por meio desse percurso, expresse-se à comunidade compreensões e análises antecedentes ao julgamento em sentido desfavorável ao acusado. GOMES FILHO. Antônio Magalhães. Presunção de Inocência e Prisão Cautelar. São Paulo: Saraiva, 1991. p.36-37.

34 Objetivando conferir maior caráter didático ao acórdão e facilitar sua compreensão, optou-se no presente tópico pela apresentação dos votos fora de sua ordem cronológica original.

35 BRASIL. Supremo Tribunal Federal. ADPF no 130/DF. Rel. Min. Carlos Ayres Britto. Julgamento em 30/04/2009. p.39 do Acórdão (inteiro teor): “Também deste ponto de inflexão já vai tomando corpo a proposição jurídica de que, pelo seu reconhecido condão de vitalizar por muitos modos a Constituição, 
ter sido uma opção seguramente realizada pela Constituição de 1988, conforme expresso em seu art.220.

Para Ayres Britto, a relevância desta opção conferiria à liberdade de imprensa uma natureza radical e absoluta ${ }^{36}$, possuindo primazia capaz de fazer com que no seu conflito com direitos individuais não houvesse espaço para a ponderação judicial, pois a Constituição já teria lhe dado prevalência. Além disso, a suficiência do tratamento constitucional da matéria deslegitimaria não apenas a Lei de Imprensa então vigente, ideologicamente incompatível com a atual axiologia constitucional ${ }^{37}$, como qualquer outra tentativa estatal de intervir nesta seara. Como consequência, a ADPF seria procedente, e a Lei $n^{\circ}$ 5.250/1967 não teria sido recepcionada pela Constituição Federal de 1988. Com este voto pactuaram o então Ministro Eros Roberto Grau, ausente da sessão, e os Ministros Ricardo Lewandowski e Carmen Lúcia.

Apresentando voto-vista, o então Ministro Carlos Alberto Direito também acompanhou o Relator quanto à procedência da ADPF e à ausência de recepção constitucional da Lei $n^{\circ}$ 5.250/1967. Não obstante, seu voto apresentou uma modificação nevrálgica, mas por vezes não percebida, de ratio decidendi. É que, em sua visão, o potencial conflito entre a liberdade de imprensa e os direitos individuais de personalidade desafiaria um constante trabalho de ponderação ${ }^{38}$, vez que em nossa atual Constituição a dignidade da pessoa humana também assumiria relevância central ${ }^{39}$. Desta feita, por mais que a Lei $n^{\circ} 5.250 / 1967$ estivesse fundada em alicerces incompatíveis com a axiologia constitucional, conduzindo à procedência da ADPF, a dimensão da imprensa livre não impediria a mediação e a regulação estatal da matéria. Ao

tirando-a mais vezes do papel, a Imprensa passa a manter com a democracia a mais entranhada relação de mútua dependência ou retroalimentação". Diponível em: http://redir.stf.jus.br/paginadorpub/paginador.jsp?docTP=AC\&docID=605411. Acesso em: 20 jun. 2020.

36 Ibidem. p.32-33: "Pois é definitiva lição da História que, em matéria de imprensa, não há espaço para o meio-termo ou a contemporização. Ou ela é inteiramente livre, ou dela já não se pode cogitar senão como jogo de aparência jurídica (...) Se é assim, não há opção diferente daquela que seguramente fez o nosso Magno Texto Republicano: consagrar a plenitude de uma liberdade tão intrinsecamente luminosa que sempre compensa (...) as quedas de voltagem que the infligem profissionais e organizações aferrados a práticas de um tempo que estrebucha".

37 Ibidem. p.74.: "O que em verdade se tem é uma realidade marcada por diplomas normativos ferozmente antagônicos em sua integralidade. Visceralmente contrários, em suas linhas e entrelinhas."

38 Ibidem. p.86: "Esse sistema próprio de equilíbrio entre a liberdade da comunicação e o respeito aos direitos da personaliade provoca imperativamente uma análise científica daquilo que nosso Presidente, Ministro Gilmar Mendes, examinando decisões da Corte Constitucional alemão, particularmente quando do julgamento do chamado "Caso Lebach", chamou de processo de ponderação".

39lbidem. p.90-91: "Vê-se, portando, que, do ponto de vista científico, a liberdade de expressão integra, necessariamente, o conceito de democracia política, porquanto significa uma plataforma de acesso ao pensamento e à livre circulação das ideias. Mas essa liberdade, vista como instituição e não como direito, divide o espaço constitucional com a dignidade da pessoa humana, que the precede em relevância pela natureza mesma do ser do homem, sem a qual não há nem liberdade, nem democracia (...) 0 que se tem concretamente é uma permanente tensão constitucional". 
contrário do defendido por Ayres Britto, esta atuação seria necessária para evitar que a dignidade da pessoa humana fosse desguarnecida de proteção ${ }^{40}$.

Esta visão de Direito foi encampada, dentre outros, pelos Ministros César Peluso ${ }^{41} \mathrm{e}$ Celso de Mello, cujos votos também concluíram pela total procedência da Arguição de Descumprimento de Preceito Fundamental. De fato, é importante notar que, ainda que Celso de Mello tenha acompanhado em sua conclusão a decisão do Relator, sua manifestação foi firme quanto à inexistência de uma resposta "pré-estabelecida" em favor da liberdade de imprensa no caso de seu conflito com direitos de personalidade ${ }^{42}$. De acordo com sua argumentação, ainda que não houvesse dúvidas de que a liberdade de imprensa deve ser protegida, como fundamento do pluralismo político e democrático, não seria defeso ao Estado atuar na conformação desta proteção, seja pela via regulamentar, seja pela atividade de ponderação a ser desenvolvida diante do conflito concreto.

Divergindo das conclusões apresentadas por Direito, mas aproximando-se de sua fundamentação, os então Ministros Joaquim Barbosa e Ellen Gracie também refutaram a impossibilidade absoluta de o Estado normatizar e racionalizar a liberdade de imprensa. Acatando a possibilidade de regulamentação, ambos deliberaram pela procedência parcial da ADPF, considerando constitucionais os dispositivos da Lei $n^{\circ} 5.250 / 1967$ que regulavam tipos penais e que vedavam publicidade preconceituosa ou beligerante. Barbosa suscitou ainda, lançando mão das ideias de Owen Fiss ${ }^{43}$, um ponto que até a sua manifestação se situava $a$ latere do julgamento: os riscos de que a imprensa, mesmo que teoricamente livre, concentrassese em mãos hegemônicas, deixando de possuir exercício plural. Este dado faria com que a

\footnotetext{
40 Ibidem. p.92-93: "Nesse sentido, penso que não será razoável estabelecer o padrão de vedação pura e simples da mediação do Estado por seus órgãos na regulação do tema (...) não se pode deixar ao desabrigo da mediação estatal esse provável conflito entre a liberdade de imprensa e a dignidade da pessoa humana".

41 Ibidem. p.122-123: “A mim me parece (...) que, além de a Constituição não prever, nem sequer em relação à vida, caráter absoluto a direito algum, evidentemente não poderia conceber a liberdade de imprensa com essa largueza absoluta e essa invulnerabilidade unímoda.(...) Noutras palavras, a liberdade da imprensa é plena nos limites conceitual-constitucionais, dentro do espaço que lhe reserva a Constituição. E é certo que a Constituição a encerra em limites predefinidos, que o são na previsão da tutela da dignidade da pessoa humana".

42 Com efeito, ao analisar o voto do Ministro Celso de Mello o Relator do caso, Ministro Ayres Britto, enfatizou à página 204 do acórdão que "estamos dissentindo, por entender que essa ponderação diante de uma colisão entre direitos de personalidade a Constituição já fez em favor da liberdade de imprensa. $E$ Vossa Excelência remete o juízo de ponderação para o Poder Judiciário".

${ }^{43}$ Ver, FISS, Owen. The Irony of Free Speech. Cambridge: Harvard University Press, 1996.
} 
participação do Estado não apenas fosse possível, mas em alguns casos se mostrasse devida e salutar ${ }^{44}$.

Também votou pela procedência parcial da medida o Ministro Gilmar Ferreira Mendes, ressalvando, porém, a manutenção no ordenamento positivo de outros dispositivos, relacionados ao "direito de resposta". Fundamentando esta deliberação o julgador salientou a relevância da liberdade de imprensa para a concretização dos valores democráticos, mas trouxe aportes de direito comparado para demonstrar que tanto na construção jurisprudencial norte-americana quanto no caráter bifronte que lhe é dado pelo Tribunal Constitucional Alemão a proteção de tal direito não ocasiona a impossibilidade de regulamentação do seu exercício, mas o exato oposto. Recordando de exemplos como o célebre caso da “Escola Base”, Gilmar Mendes indicou que, considerando o conflito latente entre liberdade de imprensa e direitos de personalidade, não caberia ao Estado se abster de atuar na composição deste quebra-cabeça ${ }^{45}$, sob pena de gerar insegurança e ausência de proteção nos dois polos - o que ocorreria com uma lacuna normativa 46. Para evitar este quadro é que o julgador, mesmo reconhecendo a existência de arestas entre a Lei de Imprensa e a Constituição de 1988, sustentou a manutenção no ordenamento das disposições pertinentes ao "direito de resposta".

De outro lado, somente o Ministro Marco Aurélio de Mello divergiu da procedência parcial ou total da Arguição, defendendo que a medida deveria ser julgada improcedente e a

\footnotetext{
44 BRASIL. Supremo Tribunal Federal. ADPF $n^{\circ}$ 130/DF. Rel. Min. Carlos Ayres Britto. Julgamento em 30/04/2009. p.119 do Acórdão (inteiro teor): “Imagine-se, por exemplo, a situação de total impotência e desamparo a que pode ser relegado um grupo social marginalizado e insularizado de uma determinada sociedade quando confrontado com a perseguição sistemática, ou a vontade deliberada de silenciá-lo, de estigmatizá-lo, de espezinhá-lo, por parte do grupo hegemônico de comunicação ou de alguns de seus porta-vozes. É tendo em mente esses riscos que a posição radical, com todo respeito, parece-me que eu, a exemplo de Owen Fiss, pense que, sem dúvida, o Estado pode, sim, ser um opressor da liberdade de expressão, e o é na maioria das vezes, mas ele pode ser também uma fonte de liberdade, desobstruindo os canais de expressão vedados àqueles que muito buscam, conscientemente, ou não, silenciar e marginalizar". Diponível em: http: //redir.stf.jus.br/paginadorpub/paginador.jsp?docTP=AC\&docID=605411. Acesso em: 20 jun. 2020. 45 Ibidem. p.226-227: "Pode-se afirmar, pois, que ao constituinte não passou despercebido que a liberdade de informação haveria de se exercer de modo compatível com o direito à imagem, à honra e à vida privada (CF, art. $\left.5^{\mathrm{a}}, \mathrm{X}\right)$, deixa entrever mesmo a legitimidade de intervenção legislativa com o propósito de compatibilizar os valores constitucionais eventualmente em conflito. A própria formulação do texto constitucional (...) parece explicitar que o constituinte não pretendeu instituir aqui um domínio inexpugnável à intervenção legislativa (...) Não poderia ser outra a orientação do constituinte, pois, do contrário, outros valores, igualmente relevantes, quedariam esvaziados diante de um direito avassalador, absoluto e insuscetível de restrição".

${ }^{46}$ Ibidem. p.267: "É certo que a atual Lei de Imprensa (Lei $\mathrm{n}^{\mathrm{a}}$ 5.250/1967) deve ser substituída por uma nova lei, que seja aberta, na medida do possível, à autorregulação, fixando, desta forma, princípios gerais e normas instrumentais de organização e procedimento. Mas declará-la totalmente não recepcionada pela Constituição de 1988, neste momento, poderia configurar um quadro de insegurança jurídica que seria extremamente danoso aos meios de comunicação, aos comunicadores e à população em geral”.
} 
eficácia da Lei $n^{\circ}$ 5.250/1967 preservada. Para tanto, após questionar a quem e a que liberdade o vácuo normativo interessaria, o Ministro ressaltou que a regulamentação específica da matéria seria relevante para a proteção dos cidadãos e da própria imprensa, fazendo com que a lacuna legal pudesse conduzir a uma situação de grave insegurança. Ato contínuo, a revogação da Lei de Imprensa deveria ocorrer apenas pela edição legislativa de uma nova normatização, sem que tivesse lugar um incômodo período de vacatio legis. Além disso, Marco Aurélio de Mello expressou o fato de a Lei de Imprensa e da Constituição Federal de 1988 terem tido vigência simultânea por cerca de duas décadas sem histórico de cerceamento da liberdade, devido à própria adaptação de sua interpretação pelos Tribunais ${ }^{47}$, o que denotaria a inexistência de descumprimento de preceito fundamental ${ }^{48}$.

Sintetizando as conclusões acima, vemos que a decisão por maioria foi pela procedência total da ADPF. Contrariando este entendimento, os Ministros Joaquim Barbosa, Ellen Gracie e Gilmar Ferreira Mendes defenderam a manutenção parcial da Lei $n^{\circ} 5.250 / 1967$, ainda que não haja coincidência entre a parte do texto legal cuja constitucionalidade foi sinalizada pelo terceiro e aquela indicada pelos dois primeiros. Por fim, o Ministro Marco Aurélio de Mello votou isoladamente pela total improcedência da Arguição, indicando a recepção constitucional plena da Lei de Imprensa.

Parece-nos, contudo, que a riqueza do julgamento não se encerra nestas conclusões. $\mathrm{Na}$ realidade, é na divergência das fundamentações adotadas que encontramos questionamentos que passam do mero exame da Lei $n^{\circ} 5.250 / 1967$ e cujas respostas, por mais que sigam em aberto, serão determinantes do futuro da liberdade de imprensa em território nacional.

\subsection{A ADPF 130/DF e a sua Ratio em Perspectiva}

De fato, a partir das considerações acima não parece haver dúvidas de que, por clara maioria, nossa Corte de vértice concluiu que a Lei $n^{\circ} 5.250 / 1967$ não possuiria compatibilidade com a Constituição Federal de 1988. Razão pela qual não deveria seguir hígida no ordenamento

\footnotetext{
47 Ibidem. p.140-141: “A quem interessa o vácuo normativo? Aos Jornais? À cidadania brasileira? A resposta, Presidente, somente pode ser, com a devida vênia, negativa (...) Não posso - a não ser que esteja a viver em outro Brasil - dizer que nossa imprensa hoje é uma imprensa cerceada, presente a Lei $\mathrm{n}^{\mathrm{a}}$ 5.250/1967. Digo - e sou arauto desse fenômeno - que se tem uma imprensa livre, agora, claro, sem que se reconheça direito absoluto, principalmente considerada a dignidade do homem".

48 Ibidem. p.143-144: "Deixemos à carga de nossos representantes, dos representantes do povo brasileiro (...), dos representantes dos Estados e, portanto, deputados e senadores, a edição de lei que substituta a em exame, sem ter-se, enquanto isso, o vácuo - como disse - que só leva à babel, à bagunça, à insegurança jurídica".
} 
brasileiro. Não obstante, por mais que esse resultado específico seja claro, o exame do debate travado pelo órgão enseja diferentes indagações.

Levando em conta a decisão proferida no âmbito da ADPF 130/DF, seria possível, a partir do texto constitucional vigente, imaginar uma nova legislação regulamentadora da liberdade imprensa? Caberia ao Estado atuar de alguma maneira nesta área? Em sendo possível, a adoção desta nova medida possuiria quais finalidades ou fundamentos? Seria viável pensar em uma verdadeira plenitude da liberdade de imprensa, de tal modo que no eventual conflito com os direitos de personalidade a própria Constituição teria ditado sua prevalência?

Procurando enfrentar esses questionamentos, consideramos que, ao superar as conclusões obtidas por cada um dos Ministros, é possível segmentar didaticamente os pensamentos expostos na ADPF 130/DF em dois grandes grupos. Facilitando a compreensão do tema e permitindo que sejam traçadas possíveis linhas para seu desenvolvimento, neste percurso, colocamos de um lado Grupo “A”, a fundamentação adotada pelo Ministro Carlos Ayres Britto, relator do caso, e pelos Ministros que a acompanharam. Do outro Grupo "B", inserimos os fundamentos contrários apresentados inicialmente pelo voto-vista do então Ministro Carlos Alberto Direito e reforçados, entre outros, pelos Ministros Celso de Mello, Gilmar Ferreira Mendes e Joaquim Barbosa. Considerando que não é a conclusão relacionada à Lei $n^{\circ} 5.250 / 1967$ que está em jogo, mas os fundamentos que a embasaram, ressaltamos que o voto do Ministro Marco Aurélio de Mello se encontra neste segundo núcleo:

(a) Grupo "A": Uma interpretação sistemática das bases deste primeiro grupo permite afirmar que seus vetores determinantes são a ideia de que a liberdade de imprensa seria um direito pleno e a visão de que esta plenitude obstaria a possível atuação estatal na matéria. A relevância de uma imprensa livre para a construção da democracia teria ensejado sua proteção absoluta pela Constituição Federal de 1988, não havendo legitimidade em uma postura regulatória do Estado e cabendo apenas às relações entre imprensa e sociedade civil ditar os deslindes de sua atuação. Com isto, no conflito entre liberdade de imprensa e direitos de personalidade, por exemplo, não haveria que se cogitar de um trabalho de ponderação pelo Poder Judiciário, pois a própria Constituição teria estabelecido a prevalência da imprensa livre e seu "poder paralisante". Do mesmo modo, não haveria legitimidade constitucional para se pensar em uma lei mediadora da atividade da imprensa, de tal modo que qualquer regulamentação positiva da matéria seria incompatível com a Constituição Federal de 1988, e não só a Lei $n^{\circ} 5.250 / 1967$; 
(b) Grupo "B": Os fundamentos inseridos neste segundo grupo não apresentam divergência quanto ao reconhecimento do importante papel desenvolvido por uma imprensa livre na construção da democracia, tornando esta premissa consensual. Contudo, distintamente do que ocorre no Grupo "A", os argumentos que aqui se inserem não apenas contrariam que a regulamentação pelo Estado fira esta liberdade, mas também indicam que esta atuação seria essencial para conformá-la adequadamente a tópicos como a pluralidade e a dignidade da pessoa humana. No mesmo sentido, a colisão em potencial entre liberdade de imprensa e direitos de personalidade não encontraria resposta em uma determinação constitucional de prevalência absoluta da primeira, havendo espaço para o exame casuístico do Poder Judiciário por meio de técnicas como a ponderação. Deixa-se de conceber a liberdade de imprensa como direito pleno ou absoluto, reconhecendo sua relevância, mas sujeitando sua proteção a uma leitura integrativa no quadro dos demais princípios constitucionais.

Com a apresentação das duas visões, percebe-se que há entre ambas uma diferença determinante a respeito das possibilidades de se pensar em uma nova Lei de Imprensa, bem como de qual deve ser o papel do Poder Judiciário, e do próprio Estado, diante dos conflitos em que a liberdade de informação esteja envolvida. Para as presentes finalidades, porém, as principais provocações a serem levantadas são outras: tendo em vista os posicionamentos exarados no âmbito da medida, qual pode ser concebida como a ratio decidendi da manifestação da Corte? Caso atribuída a ela o posto de precedente, quais os elementos que deveriam receber uma eventual vinculação?

O esboço realizado acima demonstra que, se há algo que pode assumir esse conteúdo, não se trata da percepção de que a liberdade de imprensa é um direito absoluto. Pelo contrário, analisando o posicionamento do Supremo Tribunal Federal em perspectiva, vê-se que apenas uma minoria de Ministros adotou esse encaminhamento. Para a maior parte deles essa premissa não se confirmaria, razão pela qual a conclusão alcançada no julgamento do remédio não rechaçaria a constitucionalidade de qualquer legislação voltada à imprensa, mas apenas, contingencialmente, da Lei $n^{\circ} 5.250 / 1967$.

É precisamente aqui, porém, que reside o problema ligado à não-fixação clara de uma ratio decidendi inerente ao decisum. $\mathrm{E}$ isso porque, interpretando a própria ementa da decisão acima, provida de certa incongruência com o teor do julgado ${ }^{49}$, tornou-se trivial a afirmação de

${ }^{49}$ É que, observando-se referida ementa, lê-se menções como “"PLENA" LIBERDADE DE IMPRENSA COMO CATEGORIA JURÍDICA PROIBITIVA DE QUALQUER TIPO DE CENSURA PRÉVIA. A PLENITUDE DA LIBERDADE DE IMPRENSA COMO REFORÇO OU SOBRETUTELA DAS LIBERDADES DE MANIFESTAÇÃO DO PENSAMENTO, DE INFORMAÇÃO E DE EXPRESSÃO ARTÍSTICA, CIENTÍFICA, INTELECTUAL E 
que o Supremo Tribunal Federal teria rechaçado por completo a possibilidade de conformação e de ponderação do direito de imprensa. Indo além, o próprio Ministro Ayres Britto, relator do caso, defendeu publicamente a necessidade de se "desenvolver programas, quem sabe até campanhas, esclarecendo o conteúdo da decisão do Supremo, que derrubou a Lei de Imprensa, em 2009, que foi pela plenitude da liberdade de imprensa" ${ }^{50}$. Respeitosamente, porém, essa não nos parece ter sido a posição efetivamente predominante no órgão.

Nesse ponto, é preciso perceber ainda que a lição trazida pelo julgamento da ADPF 130/DF assume importância destacada em um momento como o nosso, no qual, gradualmente, parece se vir tentando atribuir ao Superior Tribunal de Justiça e ao Supremo Tribunal Federal papeis mais próximos aos de Corte Supremas. Partindo dessa premissa, reconhece-se que é incumbência de tais instituições a uniformização interpretativa da legislação federal infraconstitucional e da própria Constituição, conferindo-lhes os poderes necessários para esse fim e alavancando travas, como a repercussão geral ${ }^{51}$ que parecem vocacionadas à estrutura-los para essa função.

Não obstante, esse elemento de nada adiantará caso não se possa compreender com clareza, após o advento de uma decisão, quais os pilares que a sustentaram; quais são as suas peças-centrais, sem as quais seu conteúdo é subtraído; qual é, enfim, sua ratio decidendi. Para construir um sistema sério de precedentes, então, é preciso notar a importância desse elemento e dedicar especial atenção à sua identificação.

COMUNICACIONAL", "A liberdade de informação jornalística é versada pela Constituição Federal como expressão sinônima de liberdade de imprensa. Os direitos que dão conteúdo à liberdade de imprensa são bens de personalidade que se qualificam como sobredireitos. Daí que, no limite, as relações de imprensa e as relações de intimidade, vida privada, imagem e honra são de mútua excludência, no sentido de que as primeiras se antecipam, no tempo, às segundas; ou seja, antes de tudo prevalecem as relações de imprensa como superiores bens jurídicos e natural forma de controle social sobre o poder do Estado, sobrevindo as demais relações como eventual responsabilização ou consequência do pleno gozo das primeiras", "primeiramente, assegura-se o gozo dos sobredireitos de personalidade em que se traduz a "livre" e "plena" manifestação do pensamento, da criação e da informação. Somente depois é que se passa a cobrar do titular de tais situações jurídicas ativas um eventual desrespeito a direitos constitucionais alheios, ainda que também densificadores da personalidade humana. Determinação constitucional de momentânea paralisia à inviolabilidade de certas categorias de direitos subjetivos fundamentais, porquanto a cabeça do art. 220 da Constituição veda qualquer cerceio ou restrição à concreta manifestação do pensamento". Com vênia, considera-se que a devida leitura do debate travado no âmbito da ADPF revela que, na realidade, nenhuma dessas conclusões foi majoritariamente sustentada pela Corte.

50 DI FRANCO, Carlos Alberto. Plenitude de Liberdade de Imprensa. Seção "Opinião”. In. Gazeta do Povo. Curitiba, Paraná. Publicado em 14 de maio de 2012.

${ }^{51}$ A respeito dessa questão, ver, FACHIN, Luiz Edson. FORTES, Luiz Henrique Krassuski. Repercussão geral do recurso extraordinário: dever de demonstração da transcendência e relevância da questão constitucional. In. Revista de Processo Comparado. v.7. São Paulo: Ed. RT, 2018. Ainda, MARINONI, Luiz Guilherme. MITIDIERO, Daniel. Repercussão Geral no Recurso Extraordinário. São Paulo: Ed. RT, 2007. 


\section{CONCLUSÃO}

É certo que há diferentes ressalvas e ponderações a serem suscitadas em desfavor da defesa vigorosa de um sistema de precedentes vinculantes, notadamente, questionando a possibilidade de que esse fator seja visto pelo processualista como uma panaceia. Não obstante, esses elementos não esvaziam a necessidade de que, em nosso atual contexto, o tema e os seus possíveis benefícios sejam objeto de reflexão.

0 presente trabalho se inseriu nesse contexto, verificando os aspectos funcionais que justificam um sistema de precedentes vinculantes e estabelecendo a importância de que, para ser minimamente efetiva, a técnica se valha de uma premissa basilar: a fixação daquilo que, em um contexto decisório, deve ou não vincular. É aqui que entra no jogo a noção de ratio decidendi, cuja má-compreensão pode levar a leituras distorcidas como aquela que não raramente é dada à decisão tomada no bojo da ADPF 130/DF. Note-se, ainda, que esse espécie de desvio sequer é exclusividade da medida em questão, ainda que o recorte metodológico aqui proposto tenha a ela se limitado ${ }^{52}$.

Nesse contexto, poderiam ser pensadas em alternativas para aprimoramento da própria performance deliberativa de nossa Corte, como a opção por um modelo de análise provido de viés issue-by-issue, superando-se nossa tradição de case-by-case. De qualquer modo, porém, o mais importante é que o problema posto seja objeto de constante avaliação. Afinal, somente assim se pode evitar a configuração de precedentes distorcidos, os quais apenas ampliariam a patologia de nosso sistema processual.

\footnotetext{
${ }^{52}$ Como exemplo, seria possível destacar a possível insuficiência da holding expressa pela Corte no exame da ADPF $\mathrm{n}^{\circ} 186$, relacionada à constitucionalidade da política de cotas raciais no acesso ao ensino superior. A questão é exposta por Fábio Portela Lopes de Almeida, salientando que, nessa oportunidade, o órgão deixou de se pronunciar a respeito de tópicos determinantes para a matéria e, do mesmo modo, chegou a conclusões que não se harmonizariam plenamente com os próprios fundamentos expostos em seu pronunciamento. Ainda, com especial importância, o autor salienta que "a ratio decidendi da Suprema Corte brasileira partiu de uma equivocada relação metonímica entre cotas e ações afirmativas, adotando ambos os conceitos como sinônimos - o que não são". Já em seu alicerce, então, seria equivocada. Ver, ALMEIDA, Fábio Portela Lopes de. Silêncios Eloquentes na ADPF $n^{\circ}$ 186: o STF de fato Julgou a Constitucionalidade das Cotas Raciais?. In. Direito UNB. v.2. Brasília: Universidade de Brasília, 2016. p.4577.
} 


\section{REFERÊNCIAS}

ALMEIDA, Fábio Portela Lopes de. Silêncios Eloquentes na ADPF $n^{\circ}$ 186: o STF de fato Julgou a Constitucionalidade das Cotas Raciais?. In. Direito UNB. v.2. Brasília: Universidade de Brasília, 2016.

ARENHART, Sérgio Cruz. OSNA, Gustavo. Curso de Processo Civil Coletivo. 2. ed. rev. atual e ampl. São Paulo: Ed. RT, 2020.

BARBOSA, Rui. A imprensa e o dever da verdade. São Paulo: Com-Arte - Editora da Universidade de São Paulo, 1990.

BOLLINGER, Lee C. Images of a Free Press. Chicago: The University of Chicago Press, 1991.

BRASIL. Supremo Tribunal Federal. ADPF n 130/DF. Rel. Min. Carlos Ayres Britto. Julgamento em 30/04/2009. Diponível em:

http: / / redir.stf.jus.br/paginadorpub/paginador.jsp?docTP=AC\&docID=605411. Acesso em: 20 jun. 2020.

BUSTAMANTE, Thomas da Rosa. Teoria do precedente judicial: a justificação e a aplicação de regras jurisprudenciais. São Paulo: Noeses, 2012.

CÂMARA, Alexandre Freitas. Levando os padrões decisórios a sério: formação e aplicação de precedentes e enunciados de súmula. São Paulo: Atlas, 2018.

COMPARATO, Fábio Konder. O papel do juiz na efetivação dos direitos humanos. In. Direitos Humanos: Visões Contemporâneas. São Paulo: Associação Juízes para a Democracia, 2001.

DI FRANCO, Carlos Alberto. Plenitude de Liberdade de Imprensa. Seção “Opinião”. In. Gazeta do Povo. Curitiba, Paraná. Publicado em 14 de maio de 2012.

DIAMOND, Larry. O Espírito da Democracia. Curitiba: Instituto Atuação, 2015.

EMERSON, Thomas. The System of Freedom of Expression. New York: Random House, 1970.

FACHIN, Luiz Edson. FORTES, Luiz Henrique Krassuski. Repercussão geral do recurso extraordinário: dever de demonstração da transcendência e relevância da questão constitucional. In. Revista de Processo Comparado. v.7. São Paulo: RT, 2018.

FISS, Owen. The Irony of Free Speech. Cambridge: Harvard University Press, 1996.

FRANK, Jerome. Courts on Trial. New York: Princeton University Press, 1949.

GINZBURG, Carlo. Olhos de madeira - novas reflexões sobre a distância. Trad. Eduardo Brandão. São Paulo: Companhia das Letras, 2001. 
GOMES FILHO. Antônio Magalhães. Presunção de Inocência e Prisão Cautelar. São Paulo: Saraiva, 1991.

KOZEL, Randy J. Precedent and Reliance. In. Emory Law Journal. v.62. Atlanta: Emory University School of Law 2013.

KOZEL. Randy J. The Scope of Precedent. In. Michigan Law Review. v.113. Ann Arbort: University of Michigan Law School, 2014.

LUX, Anthony. Spread of false information causes dangers, says Sunstein. Disponível em http://www.law.harvard.edu/news/spotlight/constitutional-law/sunstein-chair-lecture.html. Acesso em: 13 de junho de 2019.

MARINONI, Luiz Guilherme. A Ética dos Precedentes. São Paulo: Ed. RT, 2014.

MARINONI, Luiz Guilherme. MITIDIERO, Daniel. Repercussão Geral no Recurso Extraordinário. São Paulo: RT, 2007.

MARINONI, Luiz Guilherme. O STJ enquanto corte de precedentes: recompreensão do sistema processual da Corte Suprema. 3. ed. São Paulo: RT, 2017.

MARINONI, Luiz Guilherme. Precedentes obrigatórios. 3. ed. São Paulo: RT, 2013.

MITIDIERO, Daniel. Cortes Superiores e Cortes Supremas: do Controle à Interpretação, da Jurisprudência ao Precedente. 2. ed. rev. atual e ampl. São Paulo: Ed. RT, 2014.

MITIDIERO, Daniel. Precedentes, Jurisprudência e Súmulas no Novo Código de Processo Civil Brasileiro. In. Revista de Processo. v.245. São Paulo: RT, 2015.

OSNA, Gustavo. Processo civil, cultura e proporcionalidade: análise crítica da teoria processual. São Paulo: Ed. RT, 2017.

OSNA, Gustavo. Entre a Teoria e a Concretização - Possibilidades, Limites e Funções para uma Nova Lei de Imprensa. In. Revista do Instituto dos Advogados do Paraná. v. 41. Curitiba: IAP, 2012.

PEREIRA, Paula Pessoa. Legitimidade dos precedentes. São Paulo: Ed. RT, 2014.

POSNER, Richard. Economic Analysis of Law. 2. ed. Boston: Little, Brown and Company, 1977.

PUGLIESI, William. Precedentes e a civil law brasileira. São Paulo: RT, 2016.

SARTORI, Giovanni. O que é democracia? Curitiba: Instituto Atuação, 2017.

SCHAUER, Fredericks. Thinking like a Lawyer - A new introduction to legal reasoning. Cambridge: Harvard University Press, 2009.

STRECK, Lenio Luiz. NUNES, Dierle. CUNHA, Leonardo Carneiro da. (Orgs.). FREIRE, Alexandre (Coord.). Comentários ao Código de Processo Civil. 2. ed. São Paulo: Saraiva, 2017. 
SUNSTEIN, Cass R. Democracy and the problem of free speech. New York: Free Press, 1995.

TOCQUEVILLE, Alexis de. Democracy in America. Trad. Henry Reeve. 2 vol. New York: Schocken Books, 1961.

TORRANO, Bruno. Do fato à legalidade: introdução à teoria analítica do direito. Rio de Janeiro: Lumen Juris, 2014.

ZANETI JR., Hermes. O valor vinculante dos precedentes. Salvador: JusPodim, 2015.

Recebido em: 15.07.2019 / Revisões requeridas em: 21.04.2020 / Aprovado em: 01.05.2020 / Publicado em: 03.07.2020

\section{COMO FAZER REFERÊNCIA AO ARTIGO (ABNT):}

OSNA, Gustavo. Os Precedentes Judiciais e a Ratio Decidendi: o exemplo da ADPF 130/DF. Revista Eletrônica do Curso de Direito da UFSM, Santa Maria, RS, v. 15, n. 1, e39071, maio./ago. 2020. ISSN 1981-3694. DOI: http://dx.doi.org/10.5902/1981369439071. Disponível em:

https://periodicos.ufsm.br/revistadireito/article/view/39071. Acesso em: dia mês. ano.

Direitos autorais 2020 Revista Eletrônica do Curso de Direito da UFSM

Editores responsáveis: Rafael Santos de Oliveira e Angela Araujo da Silveira Espindola

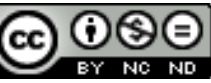

Esta obra está licenciada com uma Licença Creative Commons Atribuição-NãoComercial-SemDerivações 4.0 Internacional.

\section{SOBRE O AUTOR}

\section{GUSTAVO OSNA}

Professor Adjunto dos Programas de Graduação e de Pós-Graduação Stricto Sensu em Direito da Pontifícia Universidade Católica do Rio Grande do Sul - PUC/RS. Doutor em Direito Processual Civil pela Universidade Federal do Paraná (UFPR). Mestre em Direito Processual Civil pela Universidade Federal do Paraná (UFPR). Bacharel em Direito pela Universidade Federal do Paraná (UFPR), com o Prêmio Professor Francisco Ferreira Muniz de láurea acadêmica. Vencedor do II Prêmio Francisco Cunha Pereira (Instituto dos Advogados do Paraná) e do XIII Concurso Nacional de Monografias Jurídicas (Ministério da Justiça). Advogado e Sócio-Fundador da Mattos, Osna \& Sirena Sociedade de Advogados. Membro do Instituto Brasileiro de Direito Processual e do Instituto de Processo Comparado (UFPR). Autor de livros e de artigos publicados em revistas e em periódicos especializados. 